\title{
TUBERCULAR ROUND ATELECTASIS: A RARE CASE REPORT
}

\author{
Hasnani Rikin Bahadurbhai ${ }^{1}$,Venkateswara Reddy Tummuru², Pradyut Waghray³, A. N. V. Koteswara Rao ${ }^{4}$, P. Krishna Chaitanya ${ }^{5}$
}

1 Final Year Post Graduate Student, Department of Pulmonary Medicine, SVS Medical College and Hospital, Mahabubnagar.

${ }^{2}$ Assistant Professor, Department of Pulmonary Medicine, SVS Medical College and Hospital, Mahabubnagar.

3 Professor and HOD, Department of Pulmonary Medicine, SVS Medical College and Hospital, Mahabubnagar.

${ }^{4}$ Associate Professor, Department of Pulmonary Medicine, SVS Medical College and Hospital, Mahabubnagar.

${ }^{5}$ Final Year Post Graduate Student, Department of Pulmonary Medicine, SVS Medical College and Hospital, Mahabubnagar.

\section{ABSTRACT}

Rounded atelectasis of the lung was first described by Loeschke in 1928 in association with pleural effusion.1: Rounded atelectasis is an atelectasis of a peripheral part of the lung due to pleural adhesions and fibrosis causing deformation of the lung and bending of some small bronchi. The pleural surfaces then fuse to one another, trapping the underlying lung and leading to atelectasis. As a result of this alteration, a mass lesion that mimics lung cancer can be seen on the PA chest radiograph. This lesion is most easily appreciated to be a pseudotumour with use of CT scanning. HRCT can non-invasively demonstrate continuity to areas of diffuse pleural thickening, evidence of volume loss in the adjacent lung or a characteristic comet tail of vessels and bronchi sweeping into a wedge-shaped mass. Other names for this condition are Blesovsky's syndrome, Helical atelectasis, Folded lung, Pleuroma, Atelectatic pseudotumour, Shrinking pleuritis and Pulmonary pseudotumour. It has a yearly incidence of 5-15 cases/100,000 people. The most common cause of rounded atelectasis is occupational exposure to mineral dusts: asbestosis, pneumoconiosis, inhalation of mixe d mineral dusts.2; however, any cause of pleural inflammation can cause round atelectasis. Rounded atelectasis is less common in pulmonary diseases directly affecting pleura such as in legionellosis, histoplasmosis and in patients with end-stage renal disease. Atelectasis may also occur in the course of sarcoidosis and in young adults without history of pulmonary disease. ${ }^{3}$ In our case, it was tubercular in origin.

\section{KEYWORDS}

Round Atelectasis, Tuberculosis, Asbestosis.

HOW TO CITE THIS ARTICLE: Bahadurbhai HR, Tummuru VR, Waghray P, et al. Tubercular round atelectasis: a rare case report. J. Evolution Med. Dent. Sci. 2016;5 (58):4044-4046, DOI: 10.14260/jemds/2016/925

\section{INTRODUCTION}

Rounded atelectasis of the lung was first described by Loeschke in 1928 in association with pleural effusion. ${ }^{1}$ Rounded atelectasis is atelectasis of a peripheral part of the lung, due to pleural adhesions and fibrosis that cause deformation of the lung and torsion of some small bronchi. Other names for this condition are Blesovsky's syndrome, Helical atelectasis, Folded lung, Pleuroma, Atelectatic pseudotumour, Shrinking pleuritis and pulmonary pseudotumour. It has a yearly incidence of 5-15 cases $/ 100,000$ people. The most common cause of rounded atelectasis is occupational exposure to mineral dusts: asbestosis, pneumoconiosis, inhalation of mixed mineral dusts. ${ }^{2}$; however, any cause of pleural inflammation can cause round atelectasis. Rounded atelectasis is less common in pulmonary diseases directly affecting pleura such as in legionellosis, histoplasmosis and in patients with end-stage renal disease. Atelectasis may also occur in the course of sarcoidosis and in young adults without history of pulmonary disease. ${ }^{3}$ In our case, it was tubercular in origin.

\section{CASE REPORT}

A 48 years old female came with chief complaints of cough and right-sided chest pain since 3 weeks and fever since 2 weeks.

Financial or Other, Competing Interest: None.

Submission 03-06-2016, Peer Review 08-07-2016,

Acceptance 13-07-2016, Published 21-07-2016.

Corresponding Author:

Dr. Hasnani Rikin Bahadurbhai,

House No. 5-8-42/905,

C-Block, Nandanam Apartment,

Near Medwin Hospital,

Nampally, Hyderabad-500001.

E-mail: rikinbh@gmail.com

DOI: 10.14260/jemds/2016/925
Chest X-ray postero-anterior view showed homogeneous round opacity in right lower zone with blunting of right costophrenic angles (Fig. 1 and 2). A CT chest was done, which revealed a pleural-based opacity of $5 \mathrm{~cm}$ size with bronchovascular markings converging to it with pleural thickening (Fig. 3 and 4). A diagnosis of round atelectasis was made. CT guided biopsy of the mass was done, which showed granulomatous inflammation with caseous necrosis (Fig. 5). Hence, Tubercular aetiology was confirmed. Pt was treated with Anti-Tuberculosis therapy for 6 months and patient improved both clinically and radiologically. Fig. 6 and 7 shows post-treatment X-ray and CT respectively.

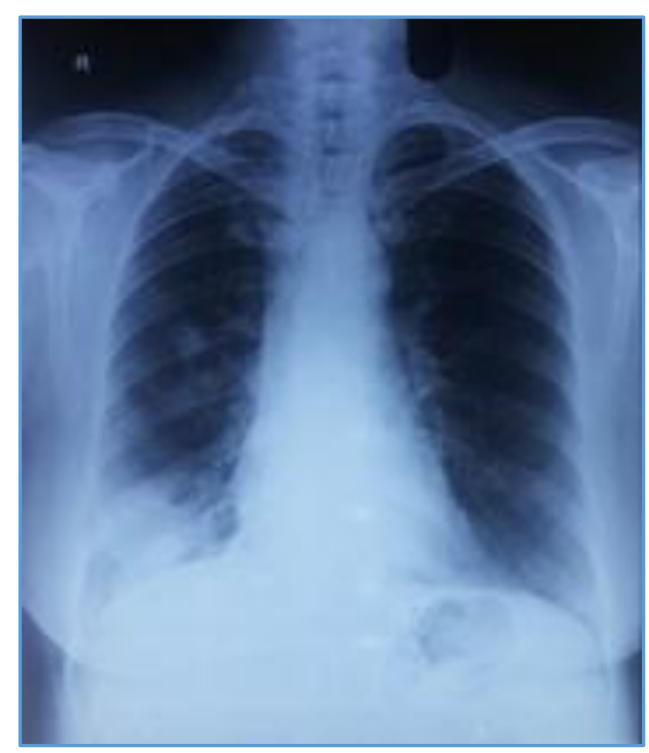

Fig. 1: Chest X-Ray PA View showing Rounded Inhomogeneous Opacity in Right Lower Zone Abutting Right Diaphragmatic Pleura 


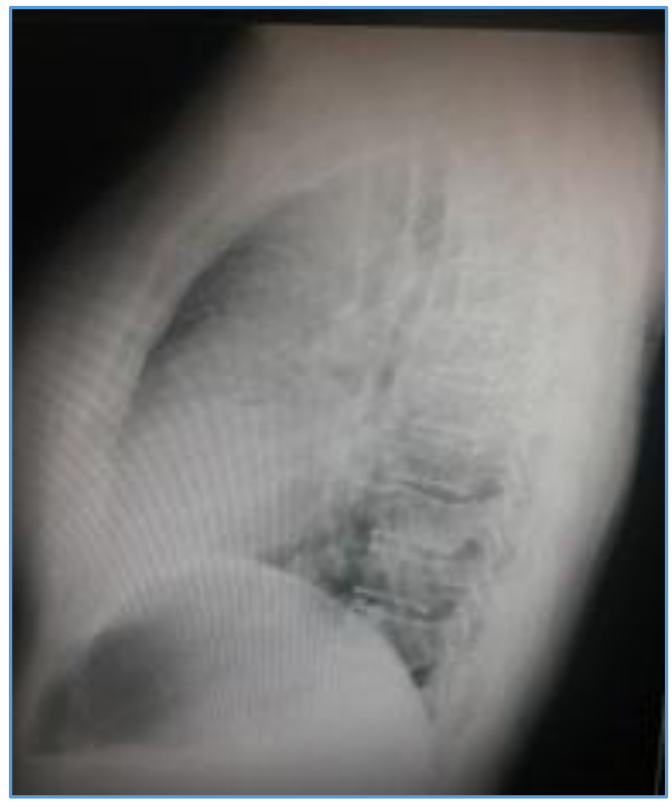

Fig. 2: Chest X-Ray Right Lateral View Localising Opacity to Right Lower Lobe

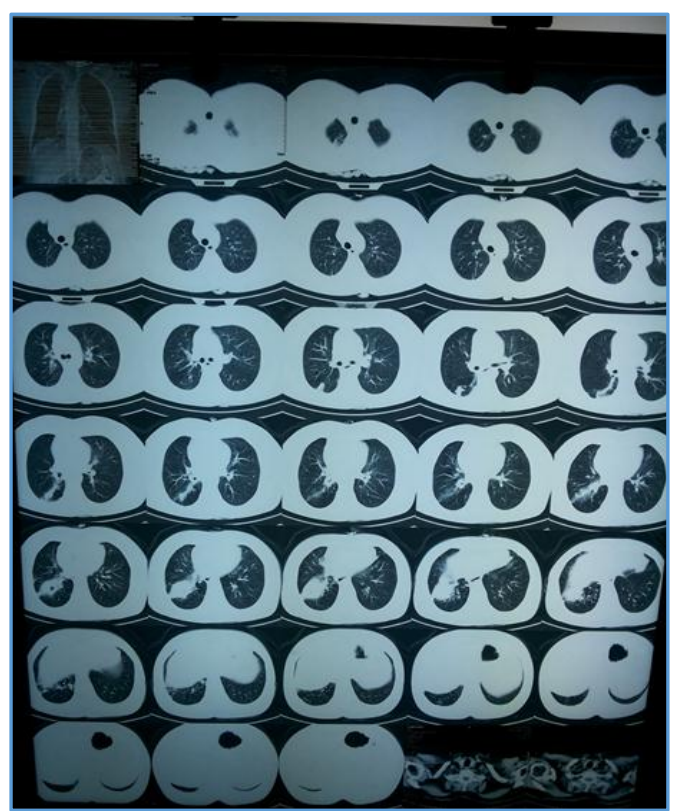

Fig. 3: CT Chest before Starting Treatment

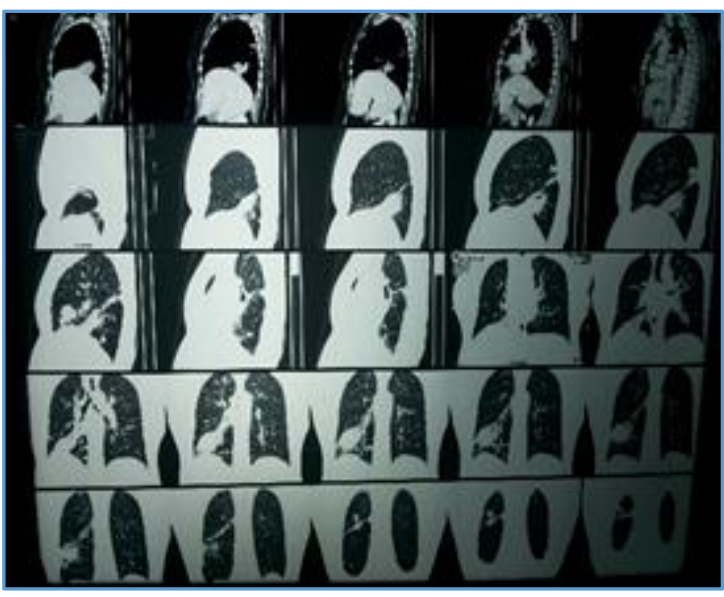

Fig. 4: CT Chest before Starting Treatment

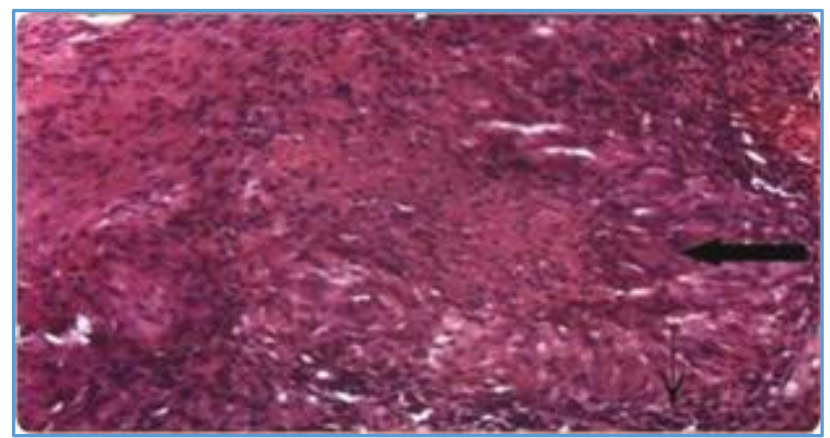

Fig. 5: HPE showing Granulomatous Lesion with Epithelioid and Langhans Type of Giant Cells

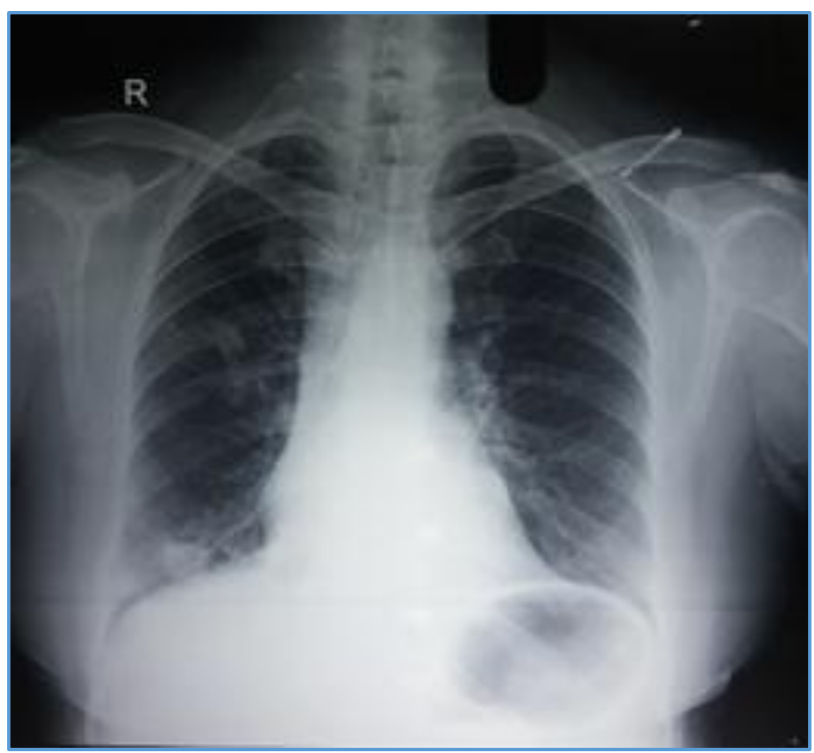

Fig. 6: Chest X-Ray PA View after Treatment

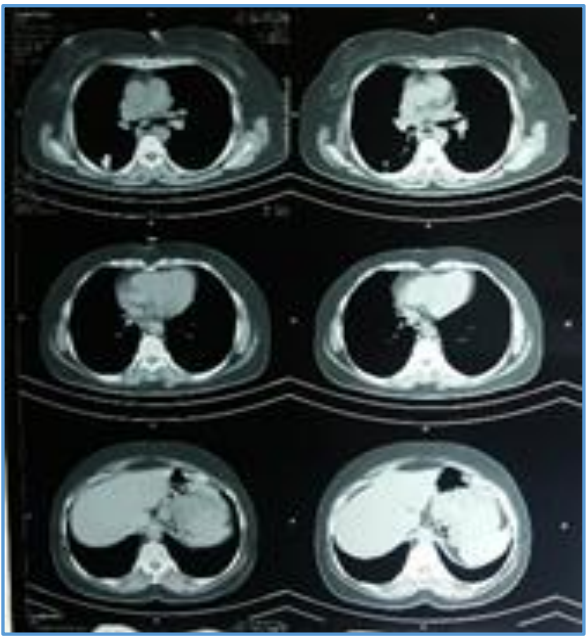

Fig. $7 a$

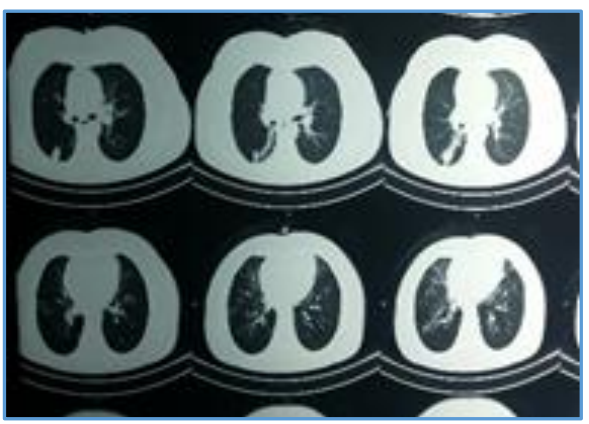

Fig. $7 b$ 


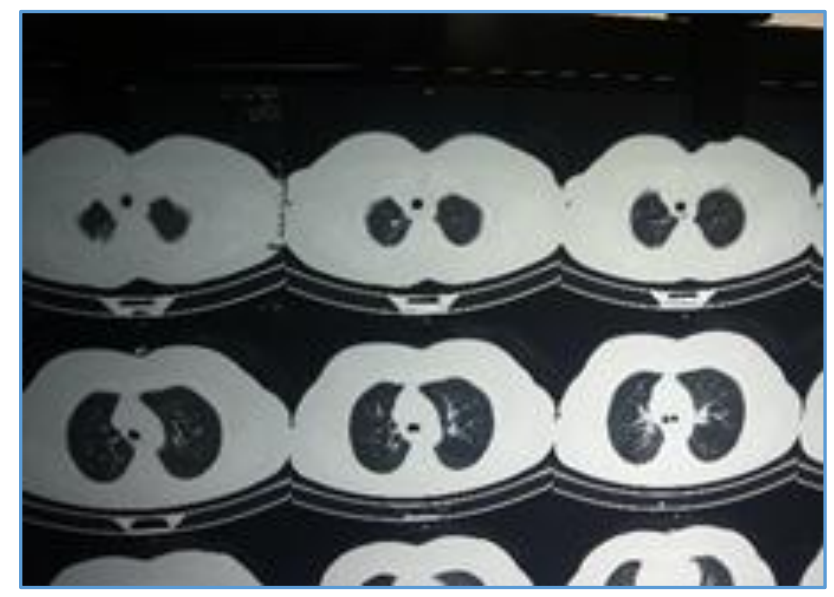

Fig. 1c

Fig. 7a, b, c: CT Chest after Treatment with AntiTuberculous Treatment

\section{DISCUSSION}

Round atelectasis is a form of peripheral atelectasis size of which varies from 2.5 to $8 \mathrm{~cm}$ in diameter on chest X-ray. ${ }^{4}$ Doyle and Lawlers have proposed seven criteria for the diagnosis of RA. 5 The diagnosis is usually based on the presence of the classical radiological triad of round mass abutting the pleura, converging bronchovascular markings and pleural thickening adjacent to the mass. ${ }^{6}$ In our case, all these findings were present in the CT.

\section{CONCLUSION}

Round atelectasis is a rare CT finding and often misdiagnosed as mass lesion. Bronchogenic carcinoma is a very close differential diagnosis. Proper examination of CT scan can easily differentiate mass lesion from round atelectasis. Asbestosis is the most common cause of round atelectasis, but patient should also be evaluated for other less common cause like Tuberculosis, especially in our country where prevalence of Tuberculosis is high.

\section{REFERENCES}

1. Loeschke HHL. Handbuch der spezielen pathologischen anatomie und histologie. Berlin: Springer-Verlag 1928;3(1):559.

2. Stathopoulos GT, Karamessini MT, Sotiriadi AE, et al. Rounded atelectasis of the lung. Respir Med 2005;99(5):615-23.

3. Tetikkurt C, Tetikkurt S, Ozdemir I, et al. Round atelectasis in sarcoidosis. Multidiscip Respir Med 2011;6(3):180-82.

4. Szydlowski GW, Cohn HE, Steiner RM, et al. Rounded atelectasis: a pulmonary psuedotumor. Ann Thorac Surg 1992;53(5):817-21.

5. Doyle TC, Lawler GA. CT features of rounded atelectasis of the lung. AJR 1984;143(2):225-8.

6. Partap VA. The comet tail sign. Radiology 1999;213(2): 553-4. 